\title{
A double-blind controlled trial of long chain n-3 polyunsaturated fatty acids in the treatment of multiple sclerosis
}

\author{
D BATES,* N E F CARTLIDGE,* J M FRENCH,* M J JACKSON,* S NIGHTINGALE,* \\ D A SHAW,* S SMITH,* E WOO,* S A HAWKINS, $\dagger$ J H D MILLAR, $\dagger$ J BELIN, $\ddagger$ \\ D M CONROY $\ddagger$ S K GILL $\ddagger$ M SIDEY, $\ddagger$ A D SMITH, $\ddagger$ R H S THOMPSON $\ddagger$ \\ K ZILKHA, $\$$ M GALE, $\S$ H M SINCLAIR $\S$
}

From the Department of Neurology, The University of Newcastle upon Tyne, ${ }^{*}$ Department of Medicine, The Queen's University of Belfast, $\uparrow$ The National Hospital, Queen Square and The Middlesex Hospital, $\ddagger$ London, The International Institute of Human Nutrition, Sutton Courtenay, $\S$ K

SUMMARY A trial of n-3 polyunsaturated fatty acids in the treatment of multiple sclerosis has been conducted over a 5 year period. Ambulant patients (312) with acute remitting disease were randomly allocated to treatment or placebo. Both groups were given dietary advice to increase the intake of n-6 polyunsaturated fatty acids and the treatment group in addition received capsules containing $\mathbf{n}-3$ polyunsaturated fatty acids. Analysis of clinical outcome at the end of 2 years of treatment was made in terms of the duration, frequency and severity of relapses and the number of patients who had improved or remained unchanged. The results showed no significant difference at the usual $95 \%$ confidence limits but there was a trend in favour of the group treated with $n-3$ polyunsaturated fatty acids in all parameters examined.

An association between dietary fat intake and the incidence of multiple sclerosis was first proposed by Swank in $1950 .^{1}$ Sinclair $^{2}$ later suggested that a deficient intake in polyunsaturated fatty acids might be the link. In line with Sinclair's views, reduced levels of linoleic acid in the serum, erythrocytes, lymphocytes and platelets of patients with multiple sclerosis have been reported. . $^{3-14}$ The addition of linoleic acid to the diet of healthy people rapidly increases serum linoleic acid $^{7}$ and an initial doubleblind trial of dietary supplementation with sunflower seed oil emulsion showed that the relapses of treated patients were less severe and of shorter duration than in the placebo group taking oleic acid. ${ }^{15}$ This initial report was supported by a second larger study ${ }^{16}$ though not by a subsequent report from Canada. ${ }^{17}$

The data from these three double-blind studies have since been re-analysed ${ }^{18}$ and 87 patients treated with linoleic acid have been compared with 85 controls, for

Address for reprint requests: Dr David Bates, Department of Neurology, Royal Victoria Infirmary, Newcastle upon Tyne NE1 4LP, UK.

Received 16 February 1988 and in revised form 11 July 1988. Accepted 21 July 1988 whom data were available over a two and a half year period. It was concluded that, among patients who at entry to the trial had minor disability, those treated with linoleic acid showed less deterioration than controls. The earlier findings of reduced severity and duration of relapses were confirmed for all treated patients, particularly for those with short disease duration.

Various suggestions have been made to explain these effects of polyunsaturated fatty acids ranging from the correction of linoleic acid levels in the lipid of cell membranes to an effect upon blood viscosity or on the immune system by alteration in lymphocyte membrane lipids or the transformation of polyunsaturated fatty acids into prostaglandins. ${ }^{19}$ Polyunsaturated fatty acids are the precursors of prostaglandins and it might be expected that the acids of the n-3 family, which give rise to prostaglandins of the " 3 " series and their derivatives, would have different effects from those of the $n-6$ family which give rise to prostaglandins of the " 2 " series. ${ }^{20}$ Linoleic acid is the parent acid for the $n-6$ series of acids including arachidonic acid, and alpha-linolenic acid is the parent acid for the n-3 group including eicosapentaenoic acid and docosahexaenoic acid. These latter two acids are 
plentiful in fish body oil and it was decided to undertake a trial of dietary supplementation with this agent in patients with multiple sclerosis. The trial was double-blind, control patients receiving olive oil which is predominantly oleic acid, a monounsaturated fatty acid which does not alter the levels of polyunsaturates in the blood or tissues.

In view of the evidence ${ }^{1516}$ of the effects of $n-6$ fatty acids in the palliation of the disease, all patients were given dietary advice to encourage a low intake of animal fat and a plentiful intake of $n-6$ polyunsaturated fatty acids. Thus the trial did not incorporate a strictly untreated control group. Both groups had the same baseline dietary adjustment on top of which the trial substance was evaluated.

It was decided that the structure of the trial should be such as to identify with $90 \%$ confidence a difference of $20 \%$ significant at the 0.05 level: this required a minimum of 125 patients per group to be studied for 2 years.

\section{Patients and methods}

Patients were recruited to the trial in three centres: the National Hospital, Queen Square, London, the Royal Victoria Hospital, Belfast and the Royal Victoria Infirmary, Newcastle upon Tyne.

\section{Patients}

All patients had clinically definite multiple sclerosis by the criteria of MacDonald and Halliday. ${ }^{21}$ All patients recruited had multiple sclerosis of the acute relapsing form and patients with chronic progressive disease were not included in the trial. Patients were between the ages of 16 and 45 years of age at entry to the trial. All had suffered at least two definite relapses of the disease and one of the relapses had occurred during the $\mathbf{2 4}$ months prior to admission to the trial. Only patients with Kurtzke Disability Status Scale score of 6 or less were accepted; ${ }^{22}$ thus they were, at worst, able to walk with aid. The informed consent of all patients taking part in the trial was obtained and all participating centres obtained the necessary ethical approval.

Three hundred and twelve patients were admitted to the trial: 101 men and 211 women. It is common in trials requiring outpatient attendance of patients who are relatively well that more women than men are willing to take part. It was the same in both groups. The composition of the two

Table 1 Patient's characteristics at entry to the trial

\begin{tabular}{|c|c|c|}
\hline & Treated & Controls \\
\hline $\begin{array}{l}\text { Number } \\
\text { Male } \\
\text { Female } \\
\text { Age (yrs) [mean, SD] } \\
\text { Duration (yrs) [mean, SD] } \\
\text { K[mean } \pm \text { SD] } \\
\text { HLA status } \\
\text { A, }_{3} \\
\text { B }_{7} \\
\text { DR }_{2}\end{array}$ & $\begin{array}{l}155 \\
53 \\
102 \\
34 \cdot 0,6 \cdot 6 \\
6 \cdot 5,4 \cdot 4 \\
2 \cdot 6,1 \cdot 6 \\
\% \\
38 \cdot 0 \\
45 \cdot 8 \\
51 \cdot 8\end{array}$ & $\begin{array}{l}157 \\
48 \\
109 \\
33 \cdot 7,6 \cdot 3 \\
6 \cdot 6,4 \cdot 6 \\
2 \cdot 5,1 \cdot 6 \\
\% \\
35 \cdot 8 \\
40 \cdot 5 \\
51 \cdot 0\end{array}$ \\
\hline
\end{tabular}

groups is shown in table I from which it can be seen that there was no significant difference between the two groups in terms of age at entry to trial, duration of disease prior to trial entry and the mean value of the Kurtzke Disability Status Scale score at entry. The number of relapses in each group of patients prior to entry was 5.23 for the treated group and 5.43 for the control group giving attack rates per year of 0.805 and 0.823 respectively. These values are not significantly different. Nor was there any significant difference between the two groups in HLA status; the percentages of patients showing positivity to A3, B7 and DR2 are shown in table 1 .

\section{Treatment}

As patients were entered into the trial they were randomised to one of two groups which were stratified for age and sex:

Treatment group Patients in this group were provided with capsules containing $0.5 \mathrm{~g}$ of MaxEPA oil, a fish body oil (supplied by Marfleet Refining Co Ltd, Hull, UK), the total fatty acids of which contain $18 \%$ eicosapentaenoic acid (C20:5, n-3) and 12\% docosahexaenoic acid (C22:6, n-3). The daily dose was 20 capsules to be taken all at once or in divided doses. This provided 1.71 $\mathrm{g}$ of $\mathrm{C} 20: 5$ and $1.14 \mathrm{~g}$ of C22:6 per day (about $5 \%$ of the oil by weight comprising the glycerol moiety).

Control group Patients in this group received capsules containing $0.5 \mathrm{~g}$ of olive oil containing $72 \%$ oleic acid. The capsules had the same appearance and flavour as the fish oil capsules and were packed and dispensed in an identical fashion. Patients were instructed to take 20 capsules per day as in the treatment group.

All capsules administered to both groups also contained 0.5 I.U. of vitamin $E$ and 100 p.p.m. of dodecylgallate in order to minimise peroxide formation.

\section{Dietary advice}

All patients were seen by a dietitian at the start of the trial and were provided with advice and a booklet setting out a diet designed to avoid a high intake of animal fat and to ensure a plentiful intake of $n-6$ polyunsaturated fatty acids.

\section{Follow-up}

Patients were seen at intervals of 3 months and on each occasion a follow-up form was completed by the physician and returned to the trial centre in Newcastle upon Tyne. The trial protocol major outcome criteria were change in overall

Table 2 Outcome at 2 years

\begin{tabular}{lrrrrr}
\hline & \multicolumn{2}{c}{ Treated $n-3, n-6$} & & \multicolumn{2}{c}{ Controls $n-6$} \\
\cline { 2 - 3 } \cline { 5 - 6 } & No. & $(\%)$ & & No. & $(\%)$ \\
\hline Same/better & 79 & $(51 \cdot 0)$ & & 65 & $(41 \cdot 4)$ \\
Worse & 66 & $(42.6)$ & & 82 & $(52 \cdot 2)$ \\
Withdrawn & 9 & $(5 \cdot 8)$ & & 10 & $(6.4)$ \\
Dead & 1 & $(0.6)$ & & 0 & $(0.0)$ \\
Total & 155 & $(100 \cdot 0)$ & & 157 & $(100.0)$ \\
\hline
\end{tabular}


Table 3 Outcome at 2 years in patients with mild disease and of short duration

\begin{tabular}{|c|c|c|c|c|}
\hline & \multicolumn{2}{|c|}{ Treated $n-3, n-6$} & \multicolumn{2}{|c|}{ Controls $n-6$} \\
\hline & No. & $(\%)$ & No. & $(\%)$ \\
\hline $\begin{array}{l}\text { Kurtzke } \leqslant 2 \\
\text { Better/same } \\
\text { Worse }\end{array}$ & $\begin{array}{l}50 \\
35\end{array}$ & $\begin{array}{l}(58 \cdot 8) \\
(41 \cdot 2)\end{array}$ & $\begin{array}{l}41 \\
49\end{array}$ & $\begin{array}{l}(45 \cdot 6) \\
(54 \cdot 4)\end{array}$ \\
\hline Total & 85 & & 90 & \\
\hline $\begin{array}{l}\text { Duration } \leqslant 5 \text { years } \\
\text { Better/same } \\
\text { Worse }\end{array}$ & $\begin{array}{l}30 \\
23\end{array}$ & $\begin{array}{l}(56.6) \\
(43.4)\end{array}$ & $\begin{array}{l}24 \\
33\end{array}$ & $\begin{array}{l}(42 \cdot 1) \\
(57 \cdot 9)\end{array}$ \\
\hline Total & 53 & & 57 & \\
\hline
\end{tabular}

disability during the period of the trial and the number, duration and severity of relapses. The assessment of change of disability depended on a detailed neurological examination undertaken at the beginning and end of the trial, and on the regular recording at all visits of the Kurtzke Disability Status Scale score. ${ }^{22}$ The duration and number of relapses were recorded as accurately as possible at each clinical attendance and an attempt was made to identify which symptoms represented new relapses and which were merely minor exacerbations of previously documented symptoms. In Belfast the severity of each relapse was also scored according to the Millar system. ${ }^{23}$

Fatty acid analysis

At admission to the trial and at approximately 6 monthly intervals thereafter fasting blood was collected from each patient, the serum was separated, stored at $-20^{\circ} \mathrm{C}$ and subsequently the fatty acids were estimated by gas liquid chromatography at the Courtauld Institute of Biochemistry, London.?

In addition, at the start of the trial and twice during the period of treatment, samples of adipose tissue aspirated from subcutaneous tissue using a dry syringe, were obtained from a cohort of patients in Newcastle and Belfast and were sent to the International Institute of Human Nutrition, Sutton Courtenay, Oxfordshire for estimation of the fatty acids. Lipids were extracted from adipose tissue with chloroform/ methanol $(2: 1 \mathrm{v} / \mathrm{v})$ and methyl esters prepared by transesterification with sodium methoxide in dry methane (15 minutes, $50^{\circ} \mathrm{C}$ ). The esters were separated by gas liquid chromatography and identified by comparison of retention times with authentic fatty acid ester mixtures.
Table 4 Mean relapse rates (median)

\begin{tabular}{|c|c|c|c|c|}
\hline & \multicolumn{2}{|c|}{$K \leqslant 2$} & \multicolumn{2}{|l|}{$K>2$} \\
\hline & $n-3$ & $n-6$ & $n-3$ & $n-6$ \\
\hline $\begin{array}{l}\text { Definite } \\
\text { Uncertain }\end{array}$ & $\begin{array}{l}0.44 \\
0.15\end{array}$ & $\begin{array}{l}0.55 \\
0.16\end{array}$ & $\begin{array}{l}0.55 \\
0.05\end{array}$ & $\begin{array}{l}0.63 \\
0.07\end{array}$ \\
\hline Total & $\begin{array}{c}0.59 \\
(0.49)\end{array}$ & $\begin{array}{c}0.71 \\
(0.67)\end{array}$ & $\begin{array}{c}0.60 \\
(0.39)\end{array}$ & $\begin{array}{c}0.70 \\
(0.52)\end{array}$ \\
\hline
\end{tabular}

\section{Statistical analysis}

Data were transferred to a computer file on the University of Newcastle upon Tyne main frame computer and were analysed by use of the SPSS-X batch system (SPSS Inc., Chicago, USA). Differences in outcome between the groups were assessed using the chi-square test with Yates correction where appropriate and the requisite $p$ values. Continuous variables were analysed using the non-parametric Mann Whitney U test.

\section{Results}

\section{Clinical outcome}

Two hundred and ninety two of the 312 patients completed 2 years of the trial; one patient died and 19 were lost to follow-up or withdrawn. The results recorded for each patient at the end of 2 years of treatment are shown in table 2 . They are expressed in terms of those patients whose Kurtzke Disability Status Scale score was higher, that is they were worse, at the end of 2 years compared with those whose score was the same or lower, that is they were unchanged or improved. In the treatment group 66 patients were worse and 79 unchanged or better whereas in the? control group 82 patients were worse and 65 the same or better. Although these figures show a trend to suggest benefit from treatment with the $n-3$ fatty acids there is no statistically significant difference between the two groups at the $5 \%$ level. $(p=0.07)$.

It was decided at the outset of the trial that, since some of the earlier trials suggested that outcome depended upon the severity and duration of the disease at trial entry, separate assessments should be made of those patients who had an initial Kurtzke Disability Status Scale score of two or less and those whose disease duration was of 5 years or less (table 3). Again

Table 5 Serum fatty acid levels

\begin{tabular}{|c|c|c|c|c|c|c|c|c|}
\hline \multirow[b]{2}{*}{$\begin{array}{l}\text { Time } \\
\text { Zero } \\
6 \text { months } \\
2 \text { years }\end{array}$} & \multicolumn{2}{|c|}{ Linoleic } & \multicolumn{2}{|c|}{ Arachidonic } & \multicolumn{2}{|c|}{ Eicosapentaenoic } & \multicolumn{2}{|c|}{ Docosahexaenoic } \\
\hline & $\begin{array}{l}T \\
34 \cdot 3 \\
35 \cdot 2 \\
35 \cdot 1\end{array}$ & $\begin{array}{l}\text { C } \\
35 \cdot 3 \\
37 \cdot 6 \\
38 \cdot 2\end{array}$ & $\begin{array}{l}T \\
6.32 \\
5.74 \\
5.53\end{array}$ & $\begin{array}{l}C \\
6 \cdot 38 \\
6 \cdot 16 \\
6 \cdot 75\end{array}$ & $\begin{array}{l}T \\
0.87 \\
5.18 \\
5.89\end{array}$ & $\begin{array}{l}C \\
0.76 \\
0.70 \\
0.71\end{array}$ & $\begin{array}{l}T \\
2 \cdot 17 \\
4.79 \\
4.95\end{array}$ & $\begin{array}{l}\mathrm{C} \\
2 \cdot 16 \\
2.03 \\
1.96\end{array}$ \\
\hline
\end{tabular}

$T \equiv$ Treated (n-3, n-6) C $\equiv$ Controls (n-6).

The values represent the amount of each fatty acid as a percentage of the total fatty acid analysed.

Standard errors are in all cases less than $5 \%$. 
Table 6 Adipose tissue fatty acid levels (Expressed as \% of Total Fatty Acid

\begin{tabular}{|c|c|c|c|c|c|c|}
\hline \multirow[b]{2}{*}{$\begin{array}{l}\text { At entry } \\
\text { (Newcastle) } \\
\text { (Belfast) }\end{array}$} & \multicolumn{2}{|c|}{$\begin{array}{l}\text { Linoleic } \\
18: 2\end{array}$} & \multicolumn{2}{|c|}{$\begin{array}{l}\text { Eicosapentaenoic } \\
20: 5\end{array}$} & \multicolumn{2}{|c|}{$\begin{array}{l}\text { Docosahexaenoic } \\
22: 6\end{array}$} \\
\hline & $\begin{array}{l}13 \cdot 4 \\
15 \cdot 7\end{array}$ & & $\begin{array}{l}\mathbf{0} \\
\mathbf{0}\end{array}$ & & $\begin{array}{l}0 \\
0.03\end{array}$ & \\
\hline 12 months & $\begin{array}{l}T \\
17 \cdot 2\end{array}$ & $\begin{array}{l}\text { C } \\
19 \cdot 3\end{array}$ & $\begin{array}{l}T \\
0.14\end{array}$ & $\begin{array}{l}\mathbf{C} \\
\mathbf{0}\end{array}$ & $\begin{array}{l}T \\
0.22\end{array}$ & $\begin{array}{l}\mathrm{C} \\
0.06\end{array}$ \\
\hline 18 months & $20 \cdot 1$ & $19 \cdot 5$ & 0.18 & 0 & 0.28 & 0.04 \\
\hline $\begin{array}{l}24 \text { months } \\
\text { (Newcastle) }\end{array}$ & 19.6 & $18 \cdot 7$ & 0.47 & 0 & 0.62 & 0.06 \\
\hline
\end{tabular}

$T \equiv$ Treated $(n-3, n-6) C \equiv$ Controls $(n-6)$.

The values represent the amount of each fatty acid as a percentage of the total fatty acid analysed. Standard errors are in all cases less than $5 \%$.

a trend is revealed in that among the mild multiple sclerosis patients the treatment group appeared to deteriorate less than the control group. Of the former $58.8 \%$ remained the same or improved compared with only $45.6 \%$ of the latter. For patients with multiple sclerosis of short duration the proportions were $56.6 \%$ and $42 \cdot 1 \%$ respectively. In neither of these instances is there a statistically significant difference between the two groups.

Analysis of the outcome data shows no significant difference between the three centres. Assessment of frequency (table 4), duration and severity of relapses, although again showing a trend in favour of the treatment group does not reveal a statistically significant difference.

Fatty acids analysis

The assessment of serum fatty acids in the patients in the trial shows that both dietary manipulation and supplementation with fish oil appreciably alters the proportion of certain of the fatty acids. Table 5 shows that in both groups there is an increase in the percentage of linoleic acid though the increase is more marked in the control group. The proportions of eicosapentaenoic and docosahexaenoic acids are significantly increased in the patients given supplements with fish oil capsules and are essentially unchanged in the control group.

Assessment of the adipose tissue has shown similar patterns of change though occurring at a rather later

Duration $<5(n=110)$

Odds ratio $(\mathrm{N}-3, \mathrm{~N}-6: \mathrm{N}-6)$

Duration $<10 \geqslant 5$ ( $n=98)$

Duration $>10(n=84)$

Newcastle $(n=182)$

$K>2(n=117)$

$K \leqslant 2(n=175)$

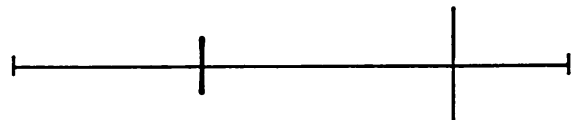

Figure The "odds ratio" of the treated group to that of the controlled. The odds in any group is the probability of an event happening to the probability of the event not happening. If the value of the ratio is unity then no difference exists between the two groups. A value of less than 1 shows a trend in favour of the treated group. For the benefit to the treated group to be significant at the $5 \%$ level the whole of the horizontal line in the figure should lie to the left of the vertical zero axis. 
stage, presumably reflecting incorporation of the dietary acids into a larger pool of lipids (table 6).

\section{Discussion}

We have confirmed earlier studies ${ }^{1516}$ which showed that dietary manipulation and supplementation with polyunsaturated fatty acids are capable of altering the percentages of serum fatty acids in multiple sclerosis patients. The initial proportions of linoleic acid in both groups entering the study were appreciably higher than those recorded in the earlier studies 1516 presumably reflecting a change in the diet of patients with multiple sclerosis during the past decade. It is possible that competition between the $n-3$ acids supplied in capsules and the $n-6$ acids provided by dietary advice resulted in a somewhat lower increase in the n-6 acids in the treatment group compared to the control group. It is also regrettable that no untreated group was included but it was felt unethical by some of the authors not to provide dietary advice to increase n-6 and this may reduce the effect of n-3 therapy.

It has previously been shown that there is a small but significant benefit for patients with multiple sclerosis who increase the n-6 fatty acids in their diet in terms of the overall deterioration and the severity and duration of attacks. ${ }^{18}$ In all parameters which have been tested in this trial, including both the overall deterioration and the frequency, severity and duration of relapses, there is a trend which suggests that patients given supplementation with fish oils in addition to dietary advice fare better than those given dietary advice alone. Unfortunately, in the present study, none of these analyses reach $95 \%$ statistical significance although, as shown in the fig, there is a trend towards benefit for the fish oil treated group.

The reason for this minor improvement in the outcome of multiple sclerosis patients with fish oil is uncertain and whether the n-3 polyunsaturated fatty acids act via their role as precursors of prostaglandins, in cell membranes, on blood viscosity or as part of myelin itself is unknown. It would have been ideal to measure the levels of the Series " 2 " and Series " 3 " prostaglandin in this study but the difficulties in organising such assessments and the unavailability of assays precluded such investigation.

Many patients with multiple sclerosis now supplement their diet with polyunsaturated fatty acids in the form of vegetable oils. This study does not provide statistically significant results but there is a trend to indicate that patients with multiple sclerosis should increase their consumption of fish oils.

The authors are particularly grateful for financial support to the Multiple Sclerosis Society of Great Britain and Northern Ireland. Dr M Sidey received a grant from the John Harris Trust and the physicians in Northern Ireland received support from Action MS Northern Ireland. Finance for the statistical analysis was also provided by a bequest from Dickinson Dees, Newcastle upon Tyne. The Marfleet Refining Co provided the fish oil and placebo trial capsules.

The authors particularly thank the dietitians Mrs J Harding, Mrs E Black, Mrs Hutchinson and Mrs M Cameron for their help and record their thanks to the late Patrick Dewar for help with HLA screening.

\section{References}

1 Swank RL. Multiple Sclerosis. A correlation of its incidence with dietary fat. Am J Med Sci 1950;220:421-30.

2 Sinclair HM. Deficiency of essential fatty acids and atherosclerosis. Lancet 1956;1:381-3.

3 Baker RWR, Thompson RHS, Zilkha KJ. Serum fatty acids in multiple sclerosis. J Neurol Neurosurg Psychiatry 1964:27: 408-14.

4 Baker RWR, Sanders H, Thompson RHS, Zilkha KJ. Serum cholesterol linoleate levels in multiple sclerosis. $J$ Neurol Neurosurg Psychiatry 1965;28:212-7.

5 Tichy J, Vymazal J, Michalec C. Serum lipoproteins, cholesterol esters and phospholipids in multiple sclerosis. Acta Neurol Scand 1969;45:32-40.

6 Gul S, Smith AD, Thompson RHS, Payling Wright H, Zilkha KJ. Fatty acid composition of phospholipids from platelets and erythrocytes in multiple sclerosis. J Neurol Neurosurg Psychiat 1970;33:506-10.

7 Belin J, Pettet N, Smith AD, Thompson RHS, Zilkha KJ. Linoleate metabolism in multiple sclerosis. J Neurol Neurosurg Psychiatry 1971:34:25-9.

8 Love WC, Cashell A, Reynolds M, Callaghan N. Linoleate and fatty acid patterns of serum lipids in multiple sclerosis and other diseases. Br Med J 1974;3:18-21.

9 Kalofoutis A, Jullien G. A study of serum fatty acids in neurological diseases. Biochimie 1974;56:623-4.

10 Thompson RHS. In: Davison AN, Humphrey JH, Liversedge AC, McDonald WI, Porterfield JS, eds. Multiple Sclerosis Research. London: HM Stationery Office, 1975:184-91.

11 Tswang WM, Belin J, Monro JA, Smith AD, Thompson RHS, Zilkha KJ. Relationship between plasma and lymphocytê linoleate in multiple sclerosis. $J$ Neurol Neurosurg Psychiatry? 1976:39:767-71.

12 Neu IS. Essential fatty acids in the serum and cerebrospinal fluid of multiple sclerosis patients. Acta Neurol Scand 1983;67:151-63.

13 Cherayil GD. Sialic acid and fatty acid concentrations in lymphocytes, red blood cells and plasma from patients with multiple sclerosis. J Neurol Sci 1984;63:1-10.

14 Tichy J, Vymazal J. Changes of some serum fatty acids in lipids in relation to the clinical course of multiple sclerosis. Acta Neurol Scand 1973;49:345-54.

15 Millar JHD, Zilkha KJ, Langman MJS, et al. Double-blind trial of linoleate supplementation of the diet in multiple sclerosis. $\mathrm{Br}$ Med J 1973;1:765-8.

16 Bates D, Fawcett PRW, Shaw DA, Weightman D. Polyunsaturated fatty acids in treatment of acute remitting multiple sclerosis. Br Med J 1978;2:1390-1.

17 Paty DW, Cousin HK, Read S, Adlakha K. Linoleic acid in multiple sclerosis: failure to show any therapeutic benefit. Acta Neurol Scand 1978;58:53-8.

18 Dworkin RH, Bates D, Millar JHD, Paty DW. A re-analysis of three double-blind trials. Neurology 1984;34:1441-5.

19 Mertin J, Meade CJ. Relevance of fatty acids in multiple sclerosis. Br Med Bull 1977;33:67-71.

20 Bunting S, Moncada S, Vane JR. The prostacyclin-thromboxane A2 balance; pathophysiological and therapeutic implications. Br Med Bull 1983;39:271-6.

21 McDonald WI, Halliday AM. Diagnosis and classification of multiple sclerosis. Br Med Bull 1977;33:4-8.

22 Kurtzke JF. On the evaluation of disability in multiple sclerosis. Neurology 1961;11:686-94.

23 Millar JHD, Vas CJ, Noronha MJ, Liversedge LA, Rawson MD. Long-term treatment of multiple sclerosis with corticotrophin. Lancet 1967;2:429-31. 